D) Check for updates

Cite this: Mater. Adv., 2021,

2,7384

Received 12th August 2021,

Accepted 10th October 2021

DOI: $10.1039 / \mathrm{d} 1 \mathrm{ma} 00717 \mathrm{c}$

rsc.li/materials-advances

\section{Facile passivation of yellow light-emitting CdSe QDs by polyethyleneimine in water to achieve bright white light emission $\dagger$}

\author{
Bo-Yi Deng, Jin Wu, Jing Liu, Ying-Yi Ren and Feng Wang (D)*
}

\begin{abstract}
A bright white light-emitting material based on CdSe QDs was prepared by a facile post-synthetic treatment of passivating the QDs by hyperbranched polyethyleneimine (PEI) in water. The CdSeaPEI aqueous solution emits white light with $\mathrm{CIE}$ coordinates $(0.334,0.347)$ and a PLQY of $(17.7 \pm 0.1) \%$.
\end{abstract}

White light-emitting materials (WLEMs) attract considerable attention from both scientific and industrial societies due to the fundamental importance of illumination, display, sensors, and so on. ${ }^{1}$ Typically, white light is realized by mixing either three primary colors, i.e., red, green, and blue, or at least two complementary colors with a suitable proportion. This means that at least two materials of different emission colors are required to achieve white light emission. Recently, research on the development of WLEMs with a single light-emitting material is blooming. ${ }^{2}$ Among, semiconductor quantum dots (QDs) are promising candidates. ${ }^{3}$

Colloidal QDs with unique optical properties, such as tunable photoluminescence (PL), high thermodynamical stability, high color purity, and solution processibility, have been applied as nano-emissive materials in displays, lightings, bioimaging, fluorescent probings, and photocatalysis. ${ }^{3-5}$ The large surfaceto-volume ratio of QDs usually gives rise to the dual emission of a band-edge exciton emission and a surface-trap emission. ${ }^{6,7}$ This PL spectral feature is prevalent in ultrasmall or magic-size CdSe QDs. ${ }^{8,9}$ By virtue of the unique dual emission, CdSe QDs are considered a potential single emitter WLEM and have been studied. ${ }^{10-15}$ In 2005, Rosenthal et al. first reported a type of ultrasmall (1.5 nm) CdSe nanocrystals (NC) exhibiting white light emission due to a broad PL profile throughout most of the visible light spectrum with a PL quantum yield (QY) of only $2-3 \% .^{10}$

Key Laboratory of Materials Chemistry for Energy Conversion and Storage (Huazhong University of Science and Technology) of Ministry of Education, Hubei Key Laboratory of Material Chemistry and Service Failure, Hubei Engineering Research Center for Biomaterials and Medical Protective Materials, School of Chemistry and Chemical Engineering, Huazhong University of Science and Technology, Wuhan, 430074, P. R. China. E-mail: wangfengchem@hust.edu.cn

$\dagger$ Electronic supplementary information (ESI) available. See DOI: 10.1039/d1ma00717c
Later, they found that the treatment on the ultrasmall CdSe NCs with organic acids enabled the improvement of QY dramatically. ${ }^{11,12}$ Kambhampati described that both temperature and surface ligand exchange alter the ratio of band-edge and surface radiation of the ultrasmall CdSe NCs, enabling high purity white light emission of the CdSe NCs to be achieved via temperature control. ${ }^{13}$ The ultrasmall CdSe NCs used in above studies were synthesized by precisely controlling the size and surface-to-volume ratio. This usually requires harsh synthetic conditions (high temperature and/or pressure) and precise time control in syntheses. Sardar and Khanna developed relatively mild synthetic methods to prepare white light-emitting CdSe NCs; however, scarce and cost organic Se-precursors are required. ${ }^{14,15}$

In this communication, we report a facile post-synthetic method to prepare bright white light-emitting CdSe QDs in an aqueous solution. The solo emissive component 3-mercaptopropionic acid (MPA)-capped CdSe QDs used in this study were synthesized by a simple and mature aqueous synthetic protocol. ${ }^{16}$ MPA-CdSe QDs prepared in an aqueous solution usually exhibit poor PLQY and emit yellow light due to a relatively larger proportion of the surface-trap emission. ${ }^{17}$ In this study, we employed a facile post-synthetic method that involves the passivation of MPA-CdSe QDs by hyperbranched polyethyleneimine (PEI, $M_{\mathrm{w}}=60 \mathrm{k}$, Fig. S1, ESI $\dagger$ ) in an aqueous solution at room temperature. After passivation, the emission color of QDs can be tuned from instinct orange-yellow to white. At an optimal condition (Fig. 1a), a CdSe@PEI aqueous solution ([CdSe] $=3.30 \times 10^{-5} \mathrm{M}$,

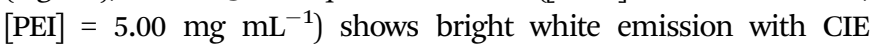
coordinates $(0.334,0.347)$, which is very close to the pure white point $(0.333,0.333)$. The PLQY of the system increased from $(1.6 \pm 0.1) \%$ in the absence of PEI to $(17.7 \pm 0.1) \%$, showing that a 10.8 time improvement was obtained. The CdSe@PEI isolated from the aqueous solution as a gel still emits white light and can be used as a solid WLEM. The white light emission of the CdSe@PEI aqueous solution is sensitive to $\mathrm{CO}_{2}$ and can be used as a reversible $\mathrm{CO}_{2}$ fluorescent sensor.

MPA-CdSe QDs were synthesized according to a widely used method by heating $\mathrm{CdCl}_{2}, \mathrm{NaSeSO}_{3}$, and MPA in an aqueous 
(a)

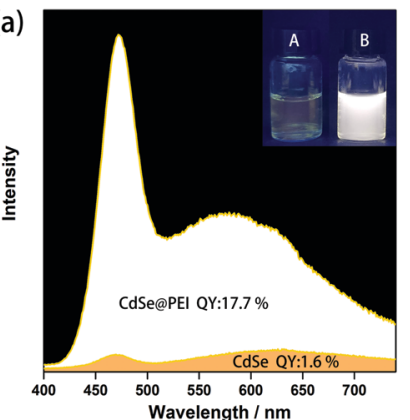

(b)

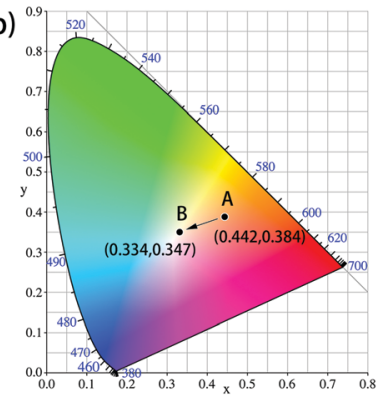

Fig. 1 (a) PL spectra of the CdSe and CdSe@PEl aqueous solutions, excitation wavelength: $380 \mathrm{~nm}$, inset: The digital images of the CdSe and CdSe@PEI aqueous solutions under UV lamp irradiation, $([\mathrm{CdSe}]=$ $\left.3.30 \times 10^{-5} \mathrm{M},[\mathrm{PEI}]=5.00 \mathrm{mg} \mathrm{mL}^{-1}\right)(\mathrm{b}) \mathrm{CIE}$ coordinates of the CdSe (A) and $\mathrm{CdSe}(\mathrm{PPEI}$ (B) aqueous solutions.

solution (ESI $\dagger) .{ }^{16}$ The size of the MPA-CdSe QDs observed from the TEM image (Fig. 3a) was in the range of $1.8-1.9 \mathrm{~nm}$. The QDs in the aqueous solution shows two PL peaks at $462 \mathrm{~nm}$ (band-edge exciton emission) and $623 \mathrm{~nm}$ (surface-trap emission), demonstrating intrinsic dual emission. The QDs emitted a dim yellow light due to the domination of the surface-trap emission $(510-740 \mathrm{~nm})$. The PLQY of the QDs in the aqueous solution was $(1.6 \pm 0.1) \%$. By adding a certain amount of PEI $\left(5.00 \mathrm{mg} \mathrm{mL}^{-1}\right)$ into the aqueous solution of the CdSe QDs $\left(1.00 \times 10^{-5} \mathrm{M}\right)$, we found that both band-edge exciton emission and surface-trap emission of the CdSe QDs increased dramatically, and the PL spectrum evolutes temporally (ESI, $\uparrow$ Fig. S3a). We monitored the spectral evolution and ploted the ratio of the band-edge exciton emission area $\left(S_{1}\right)$ to the surface-trap emission area $\left(S_{2}\right)$ with time (Fig. S3b, ESI $\dagger$ ). The $S_{1} / S_{2}$ ratio increased sharply in the first $10 \mathrm{~h}$ and finally reached a constant after $30 \mathrm{~h}$, indicating the completion of the passivation. The $\mathrm{pH}$ value of the solution was kept in a range of 10.41-10.74 during the passivation process. After passivation, the band-edge exciton emission of the QDsenhanced evidently. Before adding PEI, the $S_{1} / S_{2}$ ratio increased from 0.34 to 0.76 at the end of the PEI passivation.

This interesting phenomenon hints that the emission color of the QDs is component-concentration-dependent and can be tuned rationally by component concentration control. The intrinsic dual emission of the CdSe QDs possesses a blue light band-edge exciton emission and a broad surface-trap emission spanning the green to the red regime in the solar spectrum. The white light emission may be achieved by controlling the concentration ratio of CdSe QDs and PEI. We, therefore, investigated the concentration effect of the system. By fixing the CdSe QD concentration at $1.00 \times 10^{-5} \mathrm{M}$ and adjusting the PEI concentration from $0.50 \mathrm{mg} \mathrm{mL}^{-1}$ to $9.00 \mathrm{mg} \mathrm{mL}^{-1}$, the CIE coordinates of this series of samples shifted from the yellow area to the blue-white area (Fig. S4b, ESI $\dagger$ ). The sample of $1.00 \mathrm{mg} \mathrm{mL}{ }^{-1}$ PEI gave rise to the closest CIE coordinates $(0.336,0.335)$ to the pure white point, and the PLQY was $(14.3 \pm 0.2) \%$. In contrast, by fixing the PEI concentration at $5.00 \mathrm{mg} \mathrm{mL}^{-1}$ and adjusting the CdSe QD concentration from $1.00 \times 10^{-5} \mathrm{M}$ to $3.30 \times 10^{-5} \mathrm{M}$, the CIE coordinates

(Fig. S5b, ESI $\dagger$ ) shifted conversely from the blue-white area to the yellow area. The PL intensities of these samples increased along with an increase in the QD concentration from $1.00 \times$ $10^{-5} \mathrm{M}$ to $3.30 \times 10^{-5} \mathrm{M}$ and decreased by further increasing the QD concentration due to self-quenching of QDs at higher concentrations. The sample of $3.30 \times 10^{-5} \mathrm{M}$ QDs (Fig. 1a, inset) showed bright white emission with CIE coordinates $(0.334,0.347)$. The PLQY at this condition increased up to $(17.7 \pm 0.1) \%$, a 10.8 -fold improvement was obtained compared to the pristine CdSe QDs at the same concentration $(3.30 \times$ $10^{-5}$ M, Fig. 1a, inset).

The CdSe@PEI system also showed pH-dependent emission. As shown in Fig. 2c, the emission color of the CdSe@PEI system was sensitive to the $\mathrm{pH}$ of the solution. Under basic conditions, the samples exhibited white light emitting. By adjusting the $\mathrm{pH}$ to acidic conditions, the samples turned to yellow light emitting, which is the intrinsic emitting color of the QDs. As the accompanying $\mathrm{pH}$ decreased, the band-edge exciton emission peak diminished and the total PL quenched (Fig. 2b). This spectral change gave rise to yellow light emission of the samples at acidic $\mathrm{pH}$. For the CdSe aqueous solution without PEI, its PL also responded to the $\mathrm{pH}$, but the response was very weak and had no obvious regularity (Fig. S6, ESI $\uparrow$ ). We tested the response of the CdSe@PEI to pH under different PEI concentrations and found that the results were consistent with the rules when the PEI concentration was $5 \mathrm{mg} \mathrm{mL}{ }^{-1}$ (Fig. S7 and S8, ESI†). We found that the white light emission of the system could not be recovered by reversibly adjusting the $\mathrm{pH}$ from 4.9 to 10.4 . This may destroy the electrostatic microenvironment on the surface of the QDs due to the salt effect ( $\mathrm{NaOH}$ and $\mathrm{HCl}$ were used to adjust $\mathrm{pH}) .{ }^{18}$

To gain insights into the system, we first employed TEM to observe the morphology of the system. As shown in Fig. 3a, the MPA-CdSe QDs without PEI passivation are evenly monodispersed.
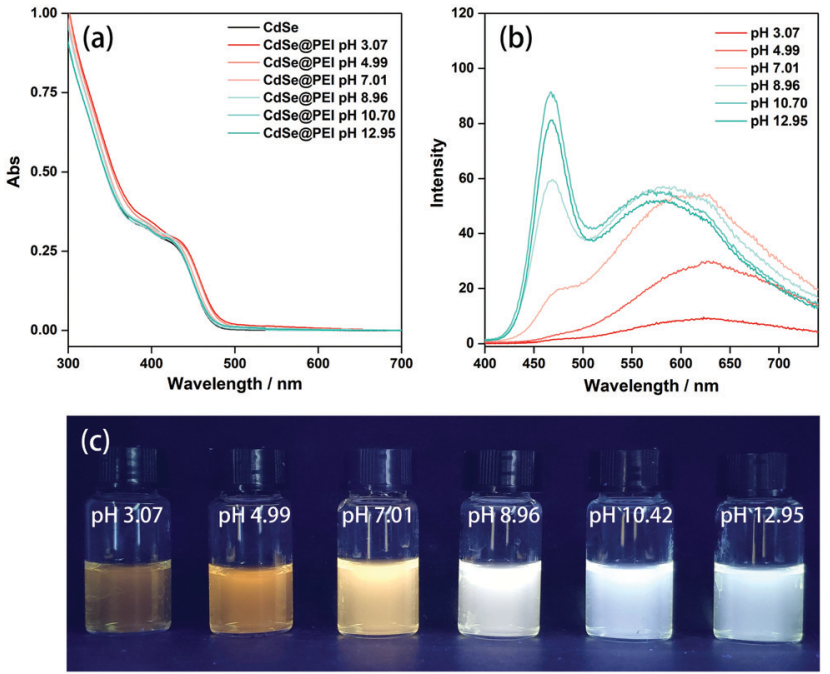

Fig. 2 ( $a$ and b) UV-Vis absorption and PL spectrum of the CdSe@PEI aqueous solution at different $\mathrm{pH}$, excitation wavelengths: $380 \mathrm{~nm}$, $\left([\mathrm{CdSe}]=1.00 \times 10^{-5} \mathrm{M},[\mathrm{PEI}]=5.00 \mathrm{mg} \mathrm{mL}^{-1}\right.$ ) (c) $\mathrm{pH}$ effect of the CdSe $\left(\mathrm{PEI}\right.$ aqueous solutions ([CdSe] $=1.00 \times 10^{-5} \mathrm{M},[\mathrm{PEI}]=5.00 \mathrm{mg} \mathrm{mL}^{-1}$ ) under UV lamp irradiation (excitation wavelength $=365 \mathrm{~nm}$ ). 

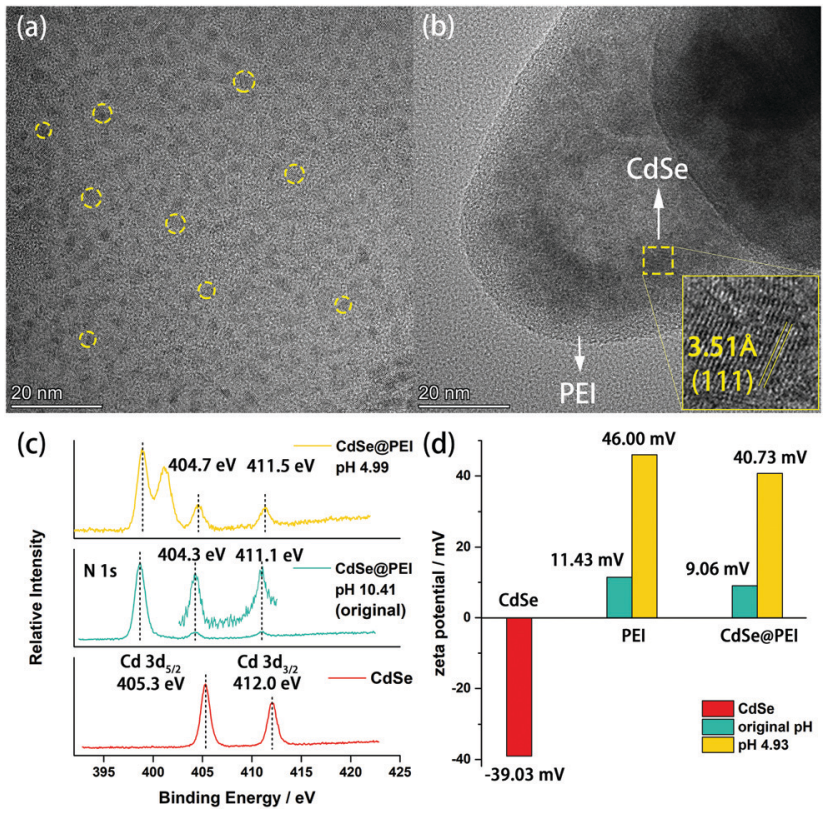

Fig. 3 TEM images of MPA-CdSe QDs (a) and CdSeaPEl (b). (c) Comparison of $\mathrm{N} 1 \mathrm{~s}$ and $\mathrm{Cd} 3 \mathrm{~d}$ binding energies of CdSe@PEl at $\mathrm{pH} 4.99$, CdSeaPEl at pH 10.41, and CdSe. (d) Surface zeta potentials of CdSe, $\mathrm{PEl}, \mathrm{CdSe} \mathrm{CPEl}$ in aqueous solutions.

In contrast, CdSe QDs in CdSe@PEI sample are enwrapped by PEI to form irregular assemblies (Fig. 3b). These assemblies are emissive under irradiation by a $405 \mathrm{~nm}$ laser, which can be observed from Confocal images (Fig. S10, ESI $\dagger$ ). We next used X-ray photoelectron spectroscopy (XPS) to examine the interaction between PEI and CdSe QDs. As shown in Fig. 3c, the XPS spectrum of CdSe QDs showed two distinct peaks at $405.3 \mathrm{eV}$ and $412.0 \mathrm{eV}$, which are assigned to the signals of $\mathrm{Cd} 3 \mathrm{~d}_{5 / 2}$ and $\mathrm{Cd} 3 \mathrm{~d}_{3 / 2}$, respectively. These two peaks negatively shifted to $404.3 \mathrm{eV}$ and $411.1 \mathrm{eV}$ in the XPS spectrum of the CdSe@PEI sample (original $\mathrm{pH}$ 10.4), indicating that the coordination between the $\mathrm{Cd}$ atom and amino groups in PEI occurred. ${ }^{19,20}$ The CdSe@PEI sample prepared at $\mathrm{pH} 4.9$ showed that these two peaks slightly shifted to $404.7 \mathrm{eV}$ and $411.5 \mathrm{eV}$, indicating the partial dissociation of amino groups from the surface Cd of CdSe QDs due to the protonation of amino groups in PEI under acidic conditions. To verify the above results, we measured surface zeta potentials $(\xi)$ of the samples (Fig. 3d). PEI in the aqueous solution was positively charged with a $\xi$ value of $11.43 \mathrm{mV}$ even under basic conditions (original $\mathrm{pH}$ 10.4) because of its buffering property over a wide $\mathrm{pH}$ range. ${ }^{21}$ By adjusting the $\mathrm{pH}$ to 4.9 , the $\xi$ value of the PEI aqueous solution increased to $46.00 \mathrm{mV}$ due to the protonation of amino groups. Although CdSe QDs are negatively charged with a $\xi$ value of $-39.03 \mathrm{mV}$, the CdSe@PEI sample is positively charged with a $\xi$ value of $9.06 \mathrm{mV}$ at $\mathrm{pH} 10.4$, and this value increases to $40.73 \mathrm{mV}$ by adjusting $\mathrm{pH}$ to 4.93 . These results indicate that the charge state of PEI dominates the overall surface zeta potential of the CdSe@PEI system.

The transient PL measurements were carried out to investigate the kinetics of the CdSe@PEI system. After excitation by a $340 \mathrm{~nm}$ laser, the band-edge exciton emission of CdSe QDs biexponential decays with two lifetimes of $4.86 \mathrm{~ns}$ and $22.00 \mathrm{~ns}^{7,22-24}$ The average lifetime $\left(\tau_{\mathrm{AC}}\right)$ of the band-edge exciton emission decay is $5.77 \mathrm{~ns}$. The surface-trap emission of CdSe QDs also biexponential decayed with two lifetimes of $35.72 \mathrm{~ns}$ and $267.57 \mathrm{~ns}$, and the average lifetime $\left(\tau_{\mathrm{AS}}\right)$ of the surface decay was 163.06 ns (Fig. 4). Likewise, both band-edge exciton emission and surface-trap emission kinetics of the CdSe@PEI sample were fitted well by a biexponential decay model (Table S1, ESI $\dagger$ ). However, all lifetimes, either band-edge exciton emission or surface-trap emission, of the CdSe@PEI sample dramatically increased in comparison to those of the CdSe sample. The average lifetimes of band-edge exciton emission and surface-trap emission decay of the CdSe@PEI sample were $89.98 \mathrm{~ns}$ and $183.96 \mathrm{~ns}$, respectively. The $\tau_{\mathrm{AC}} / \tau_{\mathrm{AS}}$ ratio can be viewed as an indicator of the population distribution of excitons at band-edge and surface-trap states in the QDs. ${ }^{7}$ This ratio dramatically increased from 0.03 in the absence of PEI to 0.49 in the presence of PEI, which is consistent with the trend of the PL spectra changes of the system.

Based on the above-mentioned results, the mechanism for the white light-emitting of the CdSe@PEI system can be explained. CdSe QDs of small size exhibited intrinsic dual emission, a bandedge exciton emission resulting from a band-edge radiative relaxation and a surface-trap emission resulting from a surfacetrap radiative relaxation. The latter red-shifted compared with the former due to the lower energy level. ${ }^{7}$ Upon excitation, electrons populate in both the band-edge state and surface-trap state. The emission color of QDs was dominated by the exciton population and radiative decay at these two states. A smaller $\tau_{\mathrm{AC}} / \tau_{\mathrm{AS}}$ ratio of the MPA-CdSe QDs indicates that the radiative relaxation at surface traps dominates, leading to orange-yellow light emission of the MPA-CdSe QDs. The PL of the QDs is sensitive to the surface chemical environment. ${ }^{25-27}$ Hyperbranched PEI contains abundant primary, secondary, and tertiary amines. The amine ligands, such as small organic amines, are capable of coordinating onto unpassivated surface cadmium sites. ${ }^{28-32}$ XPS analysis revealed that coordination between the amino groups of PEI and surface cadmium of CdSe occurred, resulting in two visible PL spectral changes. First, the overall PL intensity improved, and second, the $S_{1} / S_{2}$ ratio increased. For the above-mentioned phenomena, the analysis proceeded in steps. First, the unpassivated surface cadmium sites were considered as nonradiative electron traps. ${ }^{29}$
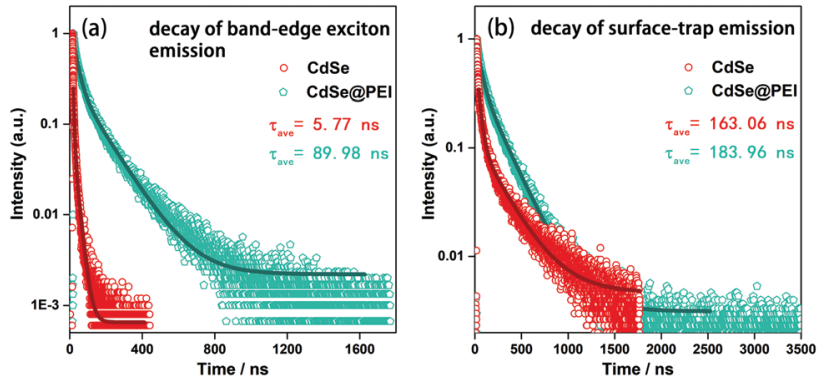

Fig. 4 Kinetic decay curve of CdSe and CdSeaPEI in aqueous solutions, (a) decay of band-edge exciton emission, (b) decay of surface-trap emission, $\lambda_{\mathrm{ex}}=340 \mathrm{~nm}$. 

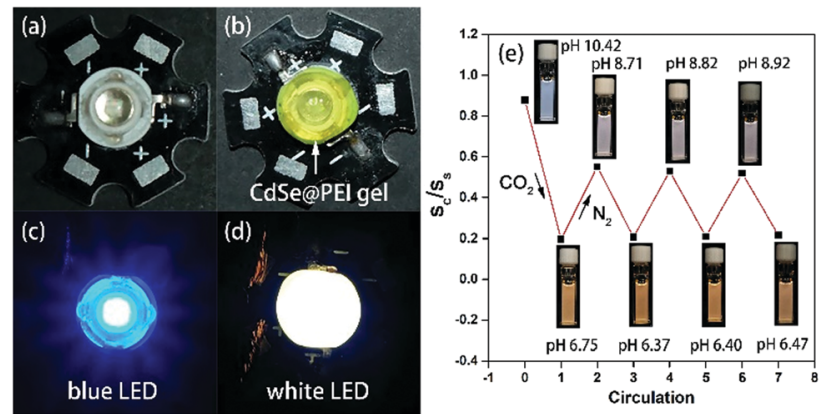

Fig. 5 Blue LED beam before (a) and after (b) coating CdSe@PEI gel. (c and d) The emission color of the LED beams after powering on. (e) The changes of emission color and $\mathrm{pH}$ of a CdSe@PEI aqueous solution by cyclical bubbling $\mathrm{CO}_{2}$ or $\mathrm{N}_{2}$ into the solution (irradiated by a UV lamp of $\lambda_{\text {ex }}=365 \mathrm{~nm}$ ).

The passivation of these sites by PEI led to enhanced radiative relaxation of the electrons, evidenced by longer lifetimes of both band-edge exciton emission and surface-trap emission of the CdSe@PEI system. Second, due to the spectral overlap between the absorption and emission spectra of the QDs (Fig. S2a, ESI $\dagger$ ), photoinduced energy transfer (PET) between QDs was inevitable. The structure of the QDs enwrapping into the PEI matrix and the increased viscosity of the solution suppressed PET. These contribute to the overall PL increment. Finally, surface passivation by PEI decreased surface traps and thus suppressed electron transfer from the band-edge state to the surface-trap state. ${ }^{7}$ A higher portion of excitons relaxed from the band-edge state and thus gives rise to a well-balanced ratio of band-edge emission and surface-trap emission. And this is the reason for the white lightemitting of the system.

The CdSe@PEI can be isolated as a yellow gel. Therefore a white light LED was made by coating the CdSe@PEI gel on a blue light LED bead (Fig. 5b). The coated LED bead emitted bright white light when powered up (Fig. 5d). The CEI of the white light LED was $(0.311,0.335)$ (Fig. S9, ESI $\dagger$ ), and the original lumen value of the LED was $30-50 \mathrm{~lm}$. This model experiment showed the potential application of the CdSe@PEI gel as a solid white light-emitting material. PEI has been studied and utilized as an outstanding $\mathrm{CO}_{2}$ absorbent. ${ }^{33}$ The amino groups in PEI enabled $\mathrm{CO}_{2}$ to be adsorbed reversibly. Based on this property, we proposed the CdSe@PEI aqueous system to be used as a $\mathrm{CO}_{2}$ fluorescent sensor. To verify this assumption, we bubbled $\mathrm{CO}_{2}$ into a CdSe@PEI aqueous solution for $30 \mathrm{~s}$. As shown in Fig. 5e, the initial white light emission of the CdSe@ PEI aqueous solution turned yellow light emission, displaying high sensitivity towards $\mathrm{CO}_{2}$. The $\mathrm{pH}$ decreased from 10.42 to 6.75. Then, $\mathrm{N}_{2}$ was bubbled into the solution for 50 minutes, and the emitting color could be recovered to white, and the $\mathrm{pH}$ increased back to 8.71. The $\mathrm{S}_{1} / \mathrm{S}_{2}$ ratio and $\mathrm{pH}$ (8.71) of the solution could not recover to the initial values. Presumably, $\mathrm{CO}_{2}$ cannot be expelled from the solution completely under such manipulation. However, the changes of emitting color and $\mathrm{pH}$ of the system showed good reversibility and stability in the progressive cycles. Under the $\mathrm{CO}_{2}$ atmosphere, $\mathrm{CO}_{2}$ was chemically adsorbed by the amino groups of PEI (2R-NH $\mathrm{NH}_{2}+$ $\mathrm{CO}_{2} \leftrightarrow \mathrm{R}-\mathrm{NHCO}_{2}{ }^{-\bullet} \mathrm{NH}_{3}-\mathrm{R}$ ), and this led to the dissociation of the amino groups from the QDs. Therefore, the QDs emit instinctive orange-yellow light. $\mathrm{CO}_{2}$ desorbed from the amino groups when $\mathrm{N}_{2}$ became saturated in the solution. The free amino groups in PEI re-passivate the QDs, thus white light emission recovered. This phenomenon further confirms the analysis described above.

\section{Conclusion}

In summary, our work demonstrates that the emission color of the MPA-CdSe QDs synthesized in an aqueous solution can be tuned from original orange-yellow to white via a facile postsynthetic treatment of adding hyperbranched PEI. The surface passivation of MPA-CdSe QDs by PEI resulted in an increment of the band-edge exciton emission and total PLQY. These provide the chance to tune the emission color of the CdSe QDs by rational component concentration control. At an optimal condition, the CdSe@PEI aqueous solution shows bright white light emission with CIE coordinates close to pure white and a PLQY up to $(17.7 \pm 0.1) \%$. This method has several advantages of facile preparation, aqueous processibility, and no rough synthesis of CdSe QDs was needed. The CdSe@PEI gel/ aqueous solution can be potentially used as a solid white lightemitting material as well as a reversible $\mathrm{CO}_{2}$ fluorescent sensor.

\section{Conflicts of interest}

There are no conflicts of interest to declare.

\section{Acknowledgements}

The authors are grateful for the financial support received from the National Natural Science Foundation of China (21871102, 22171096). They also thank the Analytical and Testing Center of the HUST for the measurements.

\section{Notes and references}

1 D. Li, J. Wang and X. Ma, Adv. Opt. Mater., 2018, 6, 1800273 .

2 Z. Chen, C.-L. Ho, L. Wang and W.-Y. Wong, Adv. Mater., 2020, 32, 1903269.

3 Y. Shu, X. Lin, H. Qin, Z. Hu, Y. Jin and X. Peng, Angew. Chem., Int. Ed., 2020, 59, 22312-22323.

4 P. Wu and X. P. Yan, Chem. Soc. Rev., 2013, 42, 5489-5521. 5 J. Liu, Y.-Y. Ren, J. Wu, W. Xia, B.-Y. Deng and F. Wang, J. Mater. Chem. A, 2021, 9, 19346-19368.

6 C. Pu, H. Qin, Y. Gao, J. Zhou, P. Wang and X. Peng, J. Am. Chem. Soc., 2017, 139, 3302-3311.

7 S. Palato, H. Seiler, L. McGovern, T. G. Mack, L. Jethi and P. Kambhampati, J. Phys. Chem. C, 2017, 121, 26519-26527.

8 S. M. Harrell, J. R. McBride and S. J. Rosenthal, Chem. Mater., 2013, 25, 1199-1210. 
9 V. Singh, Priyanka, P. V. More, E. Hemmer, Y. K. Mishra and P. K. Khanna, Mater. Adv., 2021, 2, 1204-1228.

10 M. J. Bowers, J. R. Mcbride and S. J. Rosenthal, J. Am. Chem. Soc., 2005, 127, 15378-15379.

11 T. E. Rosson, S. M. Claiborne, J. R. McBride, B. S. Stratton and S. J. Rosenthal, J. Am. Chem. Soc., 2012, 134, 8006-8009.

12 T. VanWie, E. Wysocki, J. R. McBride and S. J. Rosenthal, Chem. Mater., 2019, 31, 8558-8562.

13 M. M. Krause, J. Mooney and P. Kambhampati, ACS Nano, 2013, 7, 5922-5929.

14 S. Dolai, P. Dutta, B. B. Muhoberac, C. D. Irving and R. Sardar, Chem. Mater., 2015, 27, 1057-1070.

15 A. A. Jadhav, P. V. More and P. K. Khanna, $R S C A d v ., 2015,5$, 76733-76742.

16 Y.-S. Park, A. Dmytruk, I. Dmitruk, A. Kasuya, Y. Okamoto, N. Kaji, M. Tokeshi and Y. Baba, J. Phys. Chem. C, 2010, 114, 18834-18840.

17 L. Jethi, T. G. Mack, M. M. Krause, S. Drake and P. Kambhampati, ChemPhysChem, 2016, 17, 665-669.

18 M. Wang, N. Felorzabihi, G. Guerin, J. C. Haley, G. D. Scholes and M. A. Winnik, Macromolecules, 2007, 40, 6377-6384.

19 W. Xia, J. Wu, J. C. Hu, S. Sun, M. D. Li, H. Liu, M. Lan and F. Wang, ChemSusChem, 2019, 12, 4617-4622.

20 Y. Wu, C. Chen, X. Yan, X. Sun, Q. Zhu, P. Li, Y. Li, S. Liu, J. Ma, Y. Huang and B. Han, Angew. Chem., Int. Ed., 2021, 60, 20803-20810.
21 A. M. Smith, H. Duan, M. N. Rhyner, G. Ruana and S. Nie, Phys. Chem. Chem. Phys., 2006, 8, 3895-3903.

22 M. J. Bowers, J. R. McBride, M. D. Garrett, J. A. Sammons, A. D. Dukes, M. A. Schreuder, T. L. Watt, A. R. Lupini, S. J. Pennycook and S. J. Rosenthal, J. Am. Chem. Soc., 2009, 131(16), 5730-5731.

23 Y. Gao and X. Peng, J. Am. Chem. Soc., 2015, 137, 4230-4235.

24 M. D. Garrett, M. J. Bowers, J. R. McBride, R. L. Orndorff, S. J. Pennycook and S. J. Rosenthal, J. Phys. Chem. C, 2008, 112, 436-442.

25 A. M. Munro, I. J.-L. Plante, M. S. Ng and D. S. Ginger, J. Phys. Chem. C, 2007, 111, 6220-6227.

26 N. C. Anderson, M. P. Hendricks, J. J. Choi and J. S. Owen, J. Am. Chem. Soc., 2013, 135, 18536-18548.

27 P. Kambhampati, T. Mack and L. Jethi, ACS Photonics, 2017, 4, 412-423.

28 T. Nann, Chem. Commun., 2005, 1735-1736.

29 M. M. Krause, L. Jethi, T. G. Mack and P. Kambhampati, J. Phys. Chem. Lett., 2015, 6, 4292-4296.

30 E. Drijvers, J. D. Roo, J. C. Martins, I. Infante and Z. Hens, Chem. Mater., 2018, 30, 1178-1186.

31 X. Ji, D. Copenhaver, C. Sichmeller and X. Peng, J. Am. Chem. Soc., 2008, 130, 5726-5735.

32 P. Schapotschnikow, B. Hommersom and T. J. H. Vlugt, J. Phys. Chem. C, 2009, 113, 12690-12698.

33 M. J. Al-Marri, Y. O. Kuti, M. Khraisheh, A. Kumar and M. M. Khader, Chem. Eng. Technol., 2017, 40, 1802-1809. 